\title{
Chest pain
}

\author{
John E Hynes
}

A 68-year-old woman presented to the emergency department two hours following the onset of severe lower thoracic and epigastric pain while watching television. The pain radiated to the interscapular area and was associated with nausea and sweating. On examination she was apyrexial, pulse 120 beats/minute, blood pressure 100/70 $\mathrm{mmHg}$. There was mild epigastric tenderness and breath sounds at the right lung base were reduced. The abdominal X-ray electrocardiogram, and amylase levels were normal. A supine chest X-ray is shown in figure 1 .

Department of

Diagnostic Radiology,

North Manchester

General Hospital,

Crumpsall,

Manchester M8 6RB,

UK

JE Hynes

Accepted 15 September 1995

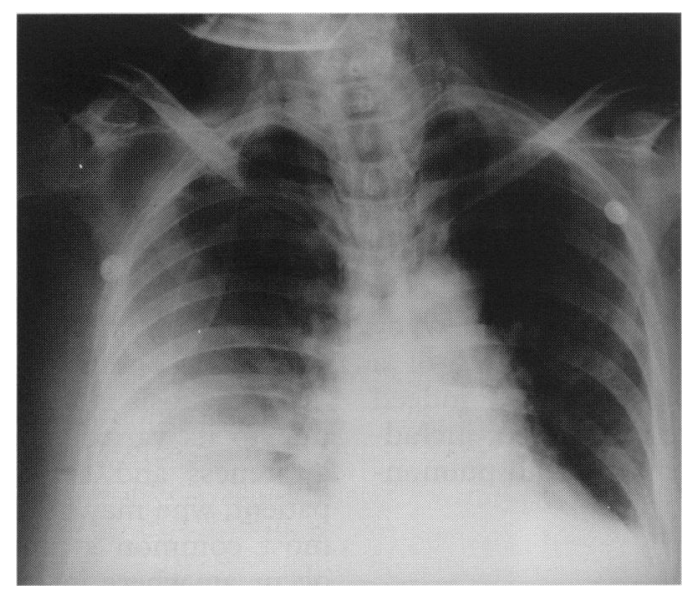

\section{Questions}

1 What is the most likely underlying diagnosis? 2 How may the diagnosis be confirmed?

Figure 1 Chest X-ray (supine) 


\begin{tabular}{|l|}
\hline Conditions of \\
'barotrauma' \\
associated \\
with oesopha- \\
geal rupture \\
\hline Overstrain \\
- status \\
asthmaticus \\
- laughter \\
- defaecation \\
- epilepsy \\
- lifting \\
- coughing \\
- hiccups \\
Vomiting \\
- pregnancy \\
- cholecystitis \\
- haemodialysis \\
- bullimia \\
\hline
\end{tabular}

Box 1

Figure 2 Oesophagogram with water-soluble contrast demonstrating a $5 \mathrm{~cm}$ tear on the right side of the mid-oesophagus

\section{Answers}

\section{QUESTION 1}

Spontaneous rupture of the oesophagus (Boerhaave syndrome). The chest $\mathrm{X}$-ray demonstrated a right-sided hydropneumothorax and surgical emphysema on the right side of the neck. Note that a 'classic' fluid level is not present due to the supine position of the patient. In the absence of a history of trauma these findings are virtually diagnostic of Boerhaave syndrome (spontaneous rupture of the oesophagus).

\section{QUESTION 2}

The diagnosis of oesophageal rupture can be made on the chest X-ray findings alone but can be confirmed with an oesophagogram, either with water-soluble contrast or with barium, which will show a leak into the mediastinum. Thoracic computed tomography can also confirm the diagnosis.

\section{Patient outcome}

Soon after admission, the patient's condition deteriorated with signs of confusion and shock. Despite a repeat chest X-ray and review by several clinicians the correct diagnosis of a ruptured oesophagus was not made, indeed several misdiagnoses were considered, including pneumonia, perforated ulcer and pulmonary infarction.

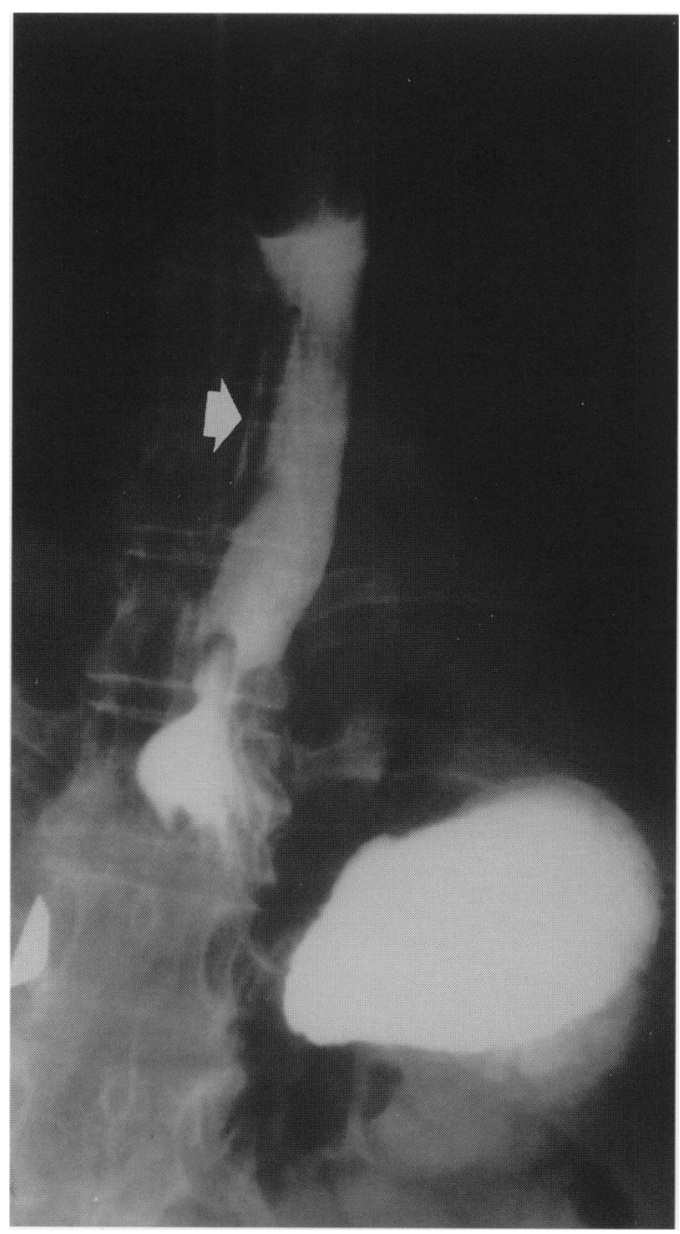

The patient's X-rays were reviewed in the radiology department $24 \mathrm{~h}$ after the patient's admission and the diagnosis of oesophageal rupture was offered immediately. An oesophagogram was requested by the patient's clinicians even though the clinical history and the radiographic findings were felt to be conclusive.

The oesophagogram demonstrated a $5 \mathrm{~cm}$ tear on the right side of the mid oesophagus (figure 2). The patient had the tear repaired but she died 10 weeks later of complications including a mediastinal abscess and shock lung syndrome.

\section{Discussion}

Spontaneous rupture of the oesophagus (Boerhaave syndrome) was first described in 1724 and, until the first successful repair by Barrett in 1946 , the condition was invariably fatal. ${ }^{1,2}$ It is distinct from Mallory Weiss syndrome which is associated with a non-transmural or mucosal tear of the oesophagus.

Typically a history of forceful or suppressed vomiting with excessive ingestion of alcohol and/or food is found but such a history may be absent. ${ }^{3}$ Rupture has been described in numerous other conditions of 'barotrauma' (box 1). The diagnosis is frequently missed or delayed due to its varied presentation, a low clinical awareness and the clinical condition of the patient, who may be shocked or confused. The most common symptom is pain, which can occur anywhere in the lower thorax or upper abdomen. Variation in the nature and severity of the pain leads to misdiagnoses, most commonly acute abdominal emergencies, myocardial infarction, aortic dissection, or pulmonary embolism. ${ }^{4}$

The typical radiographic features are shown in box 2, however the chest and abdominal films may be unremarkable in up to $12 \%$ of patients. ${ }^{5}$ If oesophageal rupture is suspected the diagnosis can be confirmed by an oesophagogram but a false negative rate of up to $10 \%$ has been reported. ${ }^{6}$

Following rupture, debris is forced through the tear into the mediastinum resulting in rapid onset of mediastinitis, sepsis and shock. The mortality rate from oesophageal rupture rises dramatically with delays in excess of 24 hours which may be as high as $20-51 \%$; recent reports have shown that delays in excess of 12 hours are also associated with increased mortality, rising from $13 \%$ up to $26 \%{ }^{7}$

\begin{tabular}{|l|}
\hline Radiological features of oesophageal \\
rupture \\
\hline - subcutaneous emphysema (neck) \\
- hydrothorax \\
- pneumothorax \\
- subumomediastinum \\
\hline
\end{tabular}




\section{Learning points}

- rupture of the oesophagus is still associated with a high morbidity and mortality, diagnosis within 12 hours being critical to outcome

- frequent misdiagnoses occur due to variation in the nature and site of pain, which may be present anywhere in the thorax or the upper abdomen

- the chest X-ray findings of pneumothorax or pneumomediastinum pleural effusion and surgical emphysema in the neck are diagnostic in the absence of a history of trauma or surgery

- the chest X-ray may be normal, highlighting the need for clinical awareness

Box 3

1 Derbes VJ, Mitchell RE Jr. Herman Boerhaave: Atrocis nec descripti prius morbi historica. The first translation of the classic case report of rupture of the oesophagus with annotations. Bull Med Libr Assoc 1995; 43: 217-40.

2 Barrett NR. Spontaneous perforation of the oesophagus. Review of the literature and report of three new cases. Thorax 1946; 1: 48-70.

3 Pate JW, Walker WA, Cole FH Jr, Owen ER, Johnson WH Spontaneous rupture of the oesophagus: a 30-year experience. Ann Thorac Surg 1989; 47: 689-92.

4 Henderson JAM, Peloquin AJM. Boerhaave revisited: spontaneous oesophageal rupture as a diagnostic masquerader (Review). Am $\mathcal{F}$ Med 1989; 86: 559-67.

\section{Final diagnosis}

Spontaneous oesophageal rupture (Boerhaave syndrome)

Keywords: spontaneous oesophageal rupture, Boerhaave syndrome

The author would like to thank Mr J Bancewicz, Consultant Surgeon, Hope Hospital, Salford and Dr SH Lee, Consultant Gastro-radiologist, Manchester Royal Infirmary for valuable help and comments in preparing this report.

5 Han SY, McElvein RB, Aldrete JS, Tishler JM. Perforation of the oesophagus: correlation of site and cause with plain film findings. $A$ FR 1985; 145: 537-40.

6 Christofordis A, Nelson SW. Spontaneous rupture of the oesophagus with emphasis on the roentgenographic diagnosis. AfR 1957; 78: 574-80.

7 Larsen K, Jensen B, Axelsen F. Perforation and rupture of the oesophagus. Scand 7 Thorac Cardiovasc Surg 1983; 17: 311-6. 